\title{
COMPARAÇÃO DO USO DE SUPERFÍCIE REAL E PLANIMÉTRICA PARA ANÁLISES DO ÍNDICE DE EFICIÊNCIA DE DRENAGEM: UM ESTUDO DE CASO NO MACIÇO DA TIJUCA - RJ
}

\section{COMPARISON THE USE OF REAL AND PLANIMETRIC SURFACE TO ANALYSIS OF DRAINAGE EFFICIENCY INDEX: A CASE STUDY IN TIJUCA MASSIF - RJ}

Manoel do Couto Fernandes

Universidade Federal do Rio de Janeiro - Depto de Geografia - Lab. de Cartografia (GEOCART) - Av. Athos da Silveira Ramos, 274 - sala H1-017 - CEP 21941-916 - Cidade Universitária - RJ -e-mail: manoel.fernandes@ufrj.br

André de Souza Avelar

Universidade Federal do Rio de Janeiro - Depto de Geografia - Lab. de Geo-Hidroecologia (GEOHECO) - Av. Athos da Silveira Ramos, 274 - sala H1-015 - CEP 21941-916 - Cidade Universitária - RJ - e-mail: andreavelar@acd.ufrj.br

Paulo Márcio Leal de Menezes

Universidade Federal do Rio de Janeiro - Depto de Geografia - Lab. de Cartografia (GEOCART) - Av. Athos da Silveira Ramos, 274 - sala H1-017 - CEP 21941-916 - Cidade Universitária - RJ - e-mail: pmenezes@acd.ufrj.br

Ana Luiza Coelho Netto

Universidade Federal do Rio de Janeiro - Depto de Geografia - Lab. de Geo-Hidroecologia (GEOHECO) - Av. Athos da Silveira Ramos, 274 - sala H1-015 - CEP 21941-916 - Cidade Universitária - RJ - e-mail: ananetto@acd.ufrj.br

\begin{abstract}
Resumo
As análises geomorfológicas são essenciais para o entendimento de algumas características que definem a estrutura e funcionalidade de uma paisagem para uma escala de tempo definida. Nesse tipo de análise o geoprocessamento é uma ferramenta essencial, pois reúne uma série de tecnologias que facilitam esse trabalho. Entretanto, algumas questões surgem e devem ser resolvidas através de investigações científicas. Uma dessas questões é a não consideração da dimensionalidade dos dados e informações utilizados, que não são avaliados em superfície real, podendo assim criar interpretações dos elementos geomorfológicos de uma paisagem de maneira correta. Mesmo possuindo uma série de opções para trabalhar com a dimensionalidade dos elementos, as técnicas de geoprocessamento tem uma limitação estabelecida pela não consideração das irregularidades da superfície. Essa diferença é maior em paisagens de relevo acidentado, e podem mascarar alguns resultados em análises geomorfológicas. Em face ao exposto, este artigo tem o propósito de verificar a diferença entre observações de superfície real e planimétrica para análise geomorfológica do índice de eficiência de drenagem (IED) para bacias de segunda ordem no maciço da Tijuca - Rio de Janeiro. Para realizar este estudo foram utilizadas cartas topográficas na escala de 1:10.000 e diferentes técnicas de geoprocessamento, como modelagem digital de elevação e sistemas de informações geográficas. Os resultados mostram uma variação de $8,46 \%$ e $17,86 \%$ nas mensurações totais de comprimento da drenagem e área das bacias de drenagem, respectivamente. A densidade de drenagem e o índice de eficiência de drenagem apresentaram, em valores totais, uma variação de 7,33\% e 7,92\%, respectivamente. Estes resultados apontam para uma sensível diferença nas análises geomorfológicas quando da utilização de observações em superfície real, que precisam ser investigadas na busca de uma leitura mais refinada da paisagem.
\end{abstract}


Palavras-chave: análise tridimensional, morfometria, geoprocessamento

\begin{abstract}
Geomorphology analyses are essentially to understand some characteristic that defines landscape structure and function at temporal scale established. In this kind of analysis the geoprocessing is an essential tool, because congregates several technologies that help in this work. However, some questions comes up and they need to be solved through scientific investigations. One of these questions is that there is no consideration of the dimension of data and information to be used, which are not valuated from observations on real surface, thus it can not interpret geomorphology elements of a landscape correctly. Even having a range of options to work with the dimensionality of the elements the geoprocessing techniques have a limitation established by the non-consideration of the surface irregularity. This difference is greater in landscape of irregular relief and can change some results in geomorfologics analyses. This paper has the purpose to verify the difference between observations on real and planimetric surface to geomorphology analysis of drainage efficiency index (DEI) for second-order basins in Tijuca massif - Rio de Janeiro. To conduct this study were used topographic maps on a scale of 1:10.000 and different geoprocessing techniques, like digital elevation models and geographic information systems. The results show a variation of $8.46 \%$ and $17.86 \%$ in total measurements of length drainage and watersheds area, respectively. The drainage density and drainage efficiency index presented in totals, a variation of $7.33 \%$ and $7.92 \%$ respectively. These results indicate a several differences in geomorphology analyses when observations on real surface were used, that must be investigated in search of a more refined reading of the landscape.
\end{abstract}

Keywords: three-dimensional analysis, morphometry, geoprocessing

\section{Introdução}

A geomorfologia da superfície terrestre é um produto da ação de processos endógenos e exógenos que interagem entre si, em diferentes escalas de tempo e ordem de magnitude. O resultado desse processo se expressa tridimensionalmente na paisagem através das diferenças altimétricas numa certa distância e na configuração geométrica das encostas. Segundo Coelho Netto (1995), esses elementos são de fundamental importância na análise da dinâmica hidrológica e erosiva de uma paisagem, e seu melhor entendimento, em visão tridimensional, se faz a partir de uma leitura integrada, dentro de cada nível hierárquico de bacia de drenagem, que é a unidade geomorfológica básica para esse tipo de análise. Um exemplo desse tipo de análise é a definição de domínios geo-hidroecológicos, conforme realizado por Fernandes et al. (2006), onde a interpretação dos domínios propostos foi definida com base nas relações funcionais geomorfológicas, ecológicas e hidrológicas, caracterizando assim uma leitura geo-hidroecológica da paisagem.

A operacionalização de análises geomorfológicas sempre foi uma tarefa complexa envolvendo uma série de técnicas diferentes. Buscando facilitar e melhorar esta operacionalização uma série de autores, como Hutchinson (1989), Guimarães (2000), Coelho Netto et al. (2007), Wilson \& Gallant (2000) vem utilizando técnicas de geoprocessamento na construção de análises geomorfológicas.

Todavia, uma série de questionamentos sobre o uso do geoprocessamento deve ser avaliada, a fim de evitar problemas nos resultados alcançados. Esses questionamentos são basicamente reflexos da construção de representações computacionais da realidade, ou seja, modelos conceituais que buscam retratar a paisagem a ser estudada (FERNANDES, 2009). Uma das questões centrais para a modelagem de paisagens é a não consideração da dimensionalidade dos dados e informações a serem trabalhados, os quais são geralmente avaliados a partir de observações de elementos em superfície planimétrica (projetada) e não em superfície real. Isto pode mascarar a interpretação das variáveis geomorfológicas, principalmente em paisagens com relevo acidentado. É importante salientar que o uso de observações em superfície real é uma possibilidade que ganha maior praticidade a partir do emprego do geoprocessamento, onde é possível analisar as estruturas da paisagem de forma tridimensional, contrastando com as observações planimétricas feitas de forma direta a partir de cartas topográficas, fotografias aéreas e outros insumos para análises geomorfológicas.

Mesmo possuindo uma série de alternativas para trabalhar com a dimensionalidade dos elementos de uma paisagem, como a utilização de modelos digitais de elevação (MDE), o geoprocessamento possui uma limitação estabelecida pela não consideração da irregularidade do espaço a ser analisado (FERNANDES \& MENEZES, 2005). Neste sentido, mesmo quando se trabalha com dados tridimensionais (3D), a superfície não é levada em conta como um contínuo dotado de relevo, sendo assim, mensurações de área e distância dos elementos que compõem a paisagem podem ser subestimadas. 
Partindo desse princípio, destaca-se a importância das observações de superfície real em avaliações geomorfológicas, para a busca do entendimento funcional das diferentes estruturas morfológicas da superfície terrestre. Deste modo, as observações em superfície real, que primam por leituras mais aprimoradas da estrutura baseada na morfologia da superfície da paisagem, podem revelar diferentes funcionalidades das unidades de análise assumidas em relação às observações planimétricas. Um exemplo dessa diferença de leitura é demonstrado na análise bacia do alto rio Cachoeira (figura 1), situada no maciço da Tijuca, onde foram encontradas diferenças significativas no valor da área calculada a partir da superfície real e da planimétrica $(11,36 \%)$, assim como no comprimento dos canais $(4,24 \%)$, revelando diferenças consideráveis na densidade de drenagem $(7,46 \%)$. Assim, diferentes leituras dos elementos estruturais da bacia (área da bacia e comprimento dos canais) revelaram distintos valores de funcionalidade, como os expressos pelo valor de densidade de drenagem na bacia em questão.

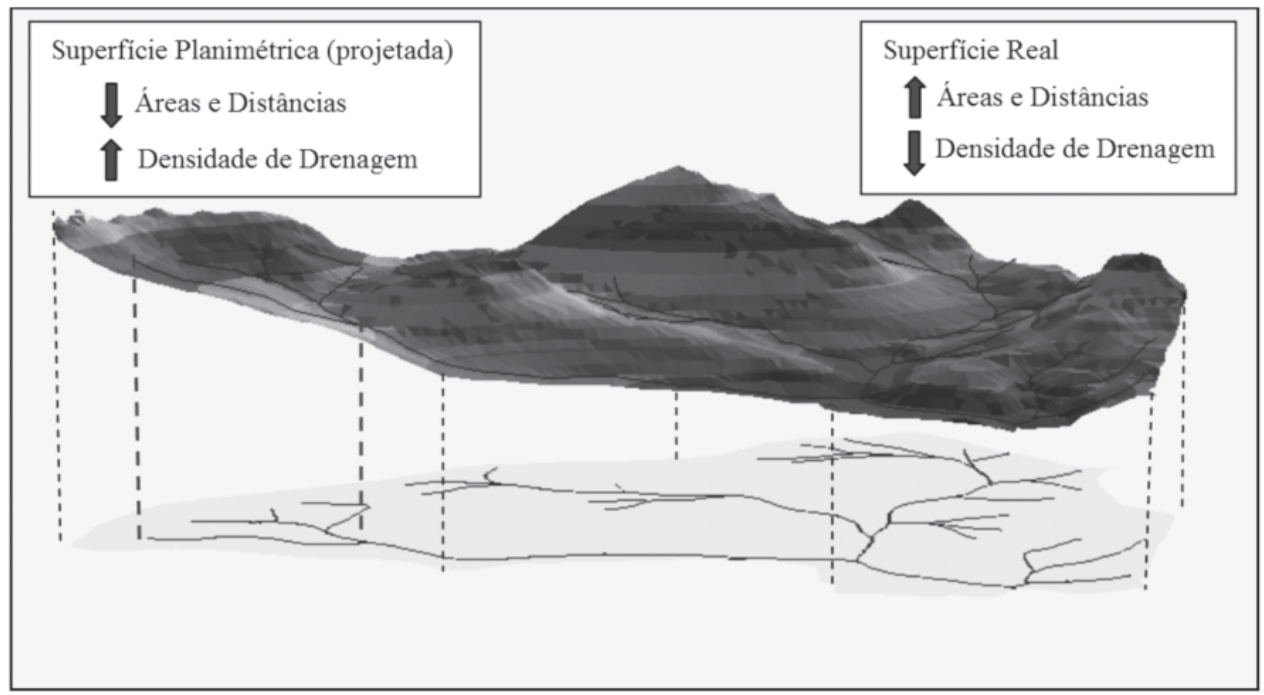

Comprimento Total da Drenagem

Superfície Real - 13,34 km

Superfície Planimétrica - 12,78 km

Diferença - 0,57 km ou $4,24 \%$

\section{Área Total das Bacias \\ Superfície Real - 3,78 $\mathrm{km}^{2}$ \\ Superfície Planimétrica - 3,35 km² \\ Diferença - 0,43 km² ou $11,36 \%$}

Dd média das Bacias

Superfície Real - 3,53 km/ $\mathrm{km}^{2}$

Superfície Planimétrica - 3,81 km/ $\mathrm{km}^{2}$

Diferença - 0,28 km/ $\mathrm{km}^{2}$ ou $7,46 \%$

Figura 1 - Diferença de observações utilizando superfície real e planimétrica na bacia do alto rio Cachoeira, maciço da Tijuca - RJ

Buscando comparar a utilização de observações em superfície real e planimétrica para leituras geomorfológicas, foi desenvolvida uma análise para o índice de eficiência de drenagem (IED). Esse índice, apresentado por Coelho Netto et al. (2007), define um valor proporcional à capacidade do relevo em drenar a água de superfície de uma bacia e, por envolver parâmetros morfométricos de área e comprimento de drenagem, possui respostas diferentes quando são adotadas as análises em superfície real e planimétrica.

Neste trabalho utilizou-se o maciço da Tijuca como estudo de caso. Situado na cidade do Rio de Janeiro (RJ), esta feição geomorfológica possui um relevo acidentado, onde a análise de observações em superfície real torna-se bastante pertinente. O maciço da Tijuca é uma unidade geomorfológica que juntamente com o maciço da Pedra Branca e Gericinó-Mendanha constituem o compartimento de maciços litorâneos da cidade do Rio de Janeiro. Esse maciço possui uma área de aproximadamente 119,2 $\mathrm{km}^{2}$, que ocupa a porção oriental do município do Rio de Janeiro/RJ, entre os paralelos $22^{\circ} 55^{\prime}$ e $23^{\circ} 00^{\prime} \mathrm{S}$; e os meridianos $43^{\circ} 20^{\prime}$ e $43^{\circ} 10^{\prime} \mathrm{W}$ (figura 2 ). 


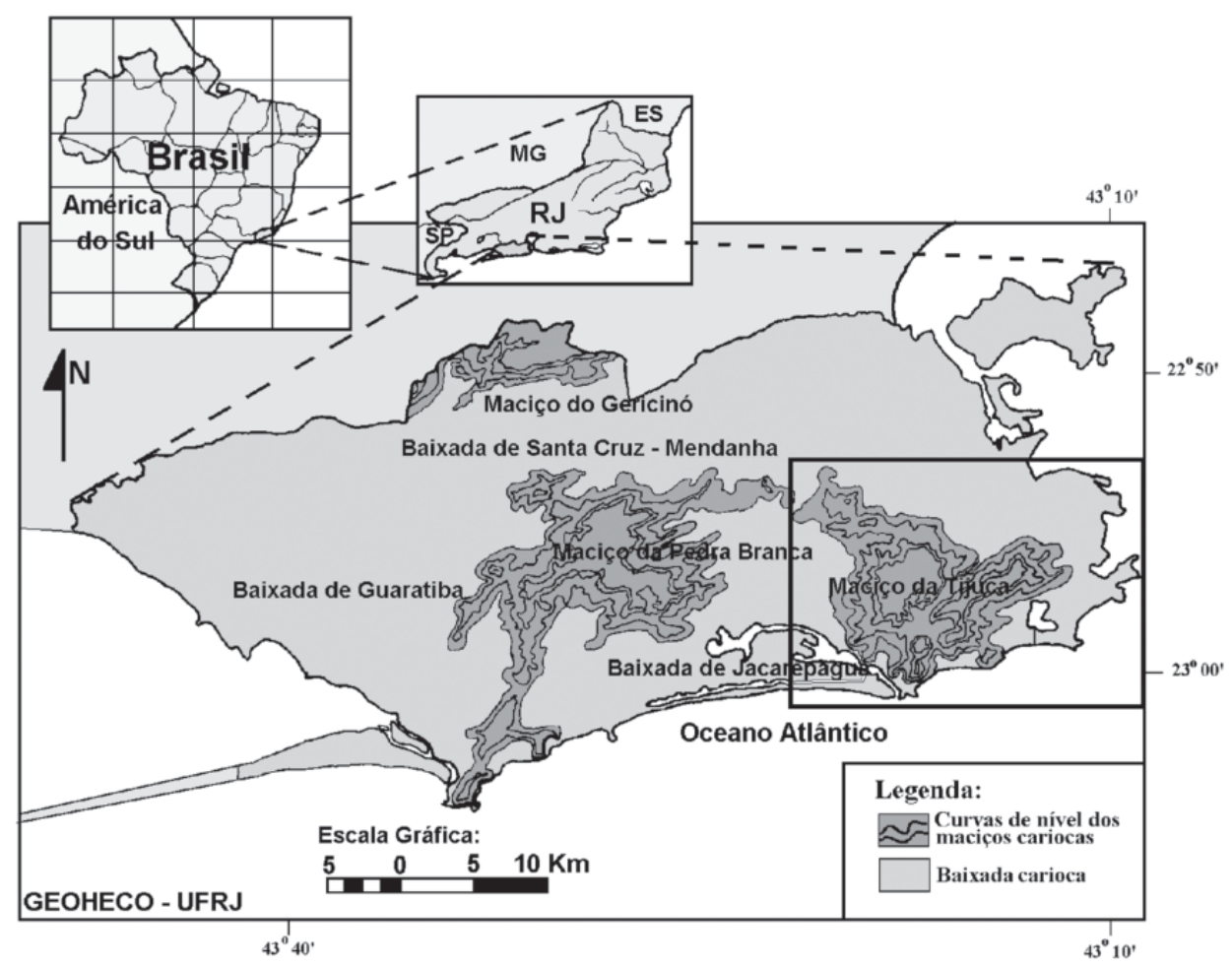

Figura 2 - Mapa de localização da cidade do Rio de Janeiro e seus compartimentos geomorfológicos

\section{Materiais e Métodos}

O desenvolvimento do trabalho foi divido em três etapas: Elaboração dos elementos para as análises geomorfológicas; aplicação da rotina de obtenção de observações em superfície real; e avaliação final.

\section{Elaboração dos elementos para as análises geomorfológicas}

Esta etapa corresponde à confecção de todos os mapeamentos utilizados (base cartográfica, mapas dos elementos estruturais e funcionais, e mapas das resultantes analíticaintegrativas) e geração do MDE utilizado para a obtenção das observações em superfície real.

A base cartográfica adotada foi a do Instituto Pereira Passos/RJ (IPP, 1999), na escala de 1:10.000. A partir desta base todos os mapas dos elementos estruturais e funcionais (gradiente topográfico e densidade de drenagem), resultante analítica-integrativa (índice de eficiência de drenagem) e o MDE foram construídos. É importante ressaltar, que a área do maciço da Tijuca foi definida pela cota de $40 \mathrm{~m}$ da base cartográfica utilizada.

Para a confecção dos mapas dos elementos estruturais e funcionais inicialmente foi realizada, em cima da base topográfica já com a drenagem reconstituída, a separação das bacias de segunda ordem segundo a classificação proposta por Strahler (1952). O gradiente topográfico (Gt) foi definido para cada bacia de segunda ordem através da relação entre a compartimentação topográfica (MEIS et al., 1982), e a mensuração da extensão do eixo maior da bacia $(\mathrm{Gt}=$ Desnivelamento $/$ Extensão do eixo maior).

A densidade de drenagem (Dd) foi obtida através da relação entre o comprimento de drenagem e a área da bacia de segunda ordem, como apresentada por Strahler (1952) $\left(\mathrm{Dd}=\right.$ Comprimento total da drenagem / Área da bacia de $2^{\mathrm{a}}$ ordem). O mapa de resultante analítica-integrativa (índice de eficiência de drenagem - IED) é definido por ser o valor resultante do produto dos elementos estruturais e funcionais de gradiente da bacia (Gt) e densidade de drenagem (Dd) $($ IED $=$ Gt $\times$ Dd $)$.

O MDE gerado foi baseado em rede irregular de triângulos (TIN) através do método de Delaunay com restrições, utilizando o interpolador de ajuste linear. A utilização deste método se justifica pelos resultados obtidos por Fernandes \& Menezes (2005), na comparação de diferentes métodos de geração de MDE para obtenção de observações em super- 
fície real no maciço da Tijuca. O modelo teve como dados de entrada as informações topográficas (curvas de nível mestras e auxiliares, pontos cotados e altitude de pontos trigonométricos) constantes das bases topográficas obtidas do IPP/RJ (IPP, 1999). Outros dados de entrada foram de fundamental importância na busca de um maior refinamento, principalmente as linhas de máximo (divisores) e linhas de mínimo (hidrografia), que também foram incorporadas na geração do modelo.

\section{Aplicação da rotina de obtenção de observações em superfície real}

Esta rotina é descrita por Fernandes (2004) e foi empregada na elaboração do mapa de densidade de drenagem e no mapa índice de eficiência de drenagem, utilizando a extensão Surface Tools for Points, Lines and Polygons para ArcView 3.2 ${ }^{\circledR}$ desenvolvida por Jenness (2001). Sua aplicação teve o intuito de comparar os valores obtidos quando da utilização de observações em superfície real e em superfície projetada (planimétrica), para cada variável usada na construção destes mapeamentos.

\section{Avaliação final}

Essa etapa corresponde a avaliação de todas as comparações de quantificação das observações em superfície real e projetada dos mapas gerados. Essa etapa foi de fundamental importância para avaliar até que ponto a não consideração da superfície real em análises geomorfológicas em domínios de relevo acidentado pode interferir nos resultados obtidos.

\section{Resultados e Discussões}

Para se chegar a resultante analítica-integrativa (IED) inicialmente foram definidos os elementos estruturais e funcionais de gradiente topográfico $(\mathrm{Gt})$ e de densidade de drenagem (Dd) para as 203 bacias de $2^{\mathrm{a}}$ ordem delimitadas no maciço da Tijuca. Os resultados da análise desses elementos em superfície real e planimétrica, e suas influências na definição da resultante IED são apresentados em seguida.

\section{Gradiente}

O valor de desnivelamento e comprimento da bacia não possuem observações em superfície real, pois são obtidos, respectivamente, pela amplitude altimétrica do ponto de maior altitude da bacia e o da sua saída (outlet), e da distância planimétrica entre esses dois pontos. Entretanto, é importante relatar o uso do MDE e da extensão 3D Analyst Tools do software ArcGis $10^{\circledR}$ para obter o valor da amplitude altimétrica da bacia. Esse procedimento garante a obtenção de valores de altitude mais precisos, pois retira a informação diretamente do MDE, o que não ocorre quando essa observação é feita manualmente sobre a base topográfica, onde são disponíveis apenas informações de altitude através dos pontos cotados ou das curvas de nível, que na maioria das vezes não contemplam esses pontos para a obtenção do desnivelamento, forçando a sua obtenção por extrapolações não tão precisas quanto as obtidas pelo MDE.

\section{Densidade de Drenagem}

Este índice representa a relação das zonas de fluxos permanentes com a área total da bacia. A duas variáveis, que dão origem à densidade de drenagem, podem ser espacializadas tridimensionalmente e por isso possuem observações em superfície real, ou seja, tanto o comprimento da drenagem, quanto à área da bacia possuem valores em superfície real quanto em superfície planimétrica. A partir desses valores podem ser geradas duas leituras de densidade de drenagem para cada bacia, e consequentemente, dois mapeamentos desse elemento estrutural e funcional, assim como, também podem ser gerados duas leituras de IED e dois mapeamentos distintos dessa resultante analítica-integrativa, pois esse índice é diretamente relacionado à densidade de drenagem.

$\mathrm{O}$ comprimento da drenagem apresentou, levando-se em consideração a soma do total das drenagens de todas as bacias de $2^{\mathrm{a}}$ ordem, um valor de $254,4 \mathrm{~km}$ para a observação em superfície planimétrica e de 275,9 km na observação em superfície real, o que se traduz em uma variação de $8,46 \%$ ou $21,5 \mathrm{~km}$. A avaliação individual por bacia revelou que essa diferença se concentra na faixa de 5 a $15 \%$, e possui amplitude de $1,14 \%$ a $40,11 \%$, diferença a qual em quilômetros varia de 0,005 a $0,479 \mathrm{~km}$ (figura 3 ).

Os resultados obtidos são um reflexo direto do comportamento da drenagem em relação ao seu posicionamento na bacia e a própria característica dessa bacia. Assim, as maiores diferenças foram observadas em drenagens que se espraiam pelas áreas de maior declividade da bacia, em contraposição às drenagens que mesmo em bacias com declividade elevada não se localizam nessas áreas, mas sim nas partes mais a jusante e menos íngremes.

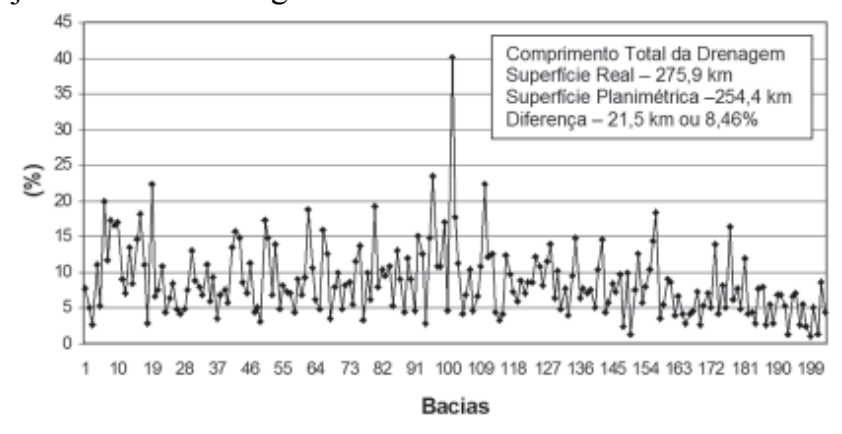

Figura 3 - Diferença percentual dos valores de comprimento da drenagem em superfície real e planimétrica por bacia de $2^{a}$ ordem 
A análise da área das bacias demonstrou, levando-se em consideração a soma da área de todas as bacias de $2^{\mathrm{a}}$ ordem, um valor de $61,24 \mathrm{~km}^{2}$ para a observação em superfície planimétrica e de $72,18 \mathrm{~km}^{2}$ na observação em superfície real, o que traduz em uma variação de $17,86 \%$ ou $10,94 \mathrm{~km}^{2}$. A avaliação individual por bacia revelou que essa diferença se concentra na faixa de 10 a $25 \%$, e possui amplitude de $2,38 \%$ a $64,35 \%$, resultando em uma variação absoluta de 0,003 a $0,255 \mathrm{~km}^{2}$ (figura 4).

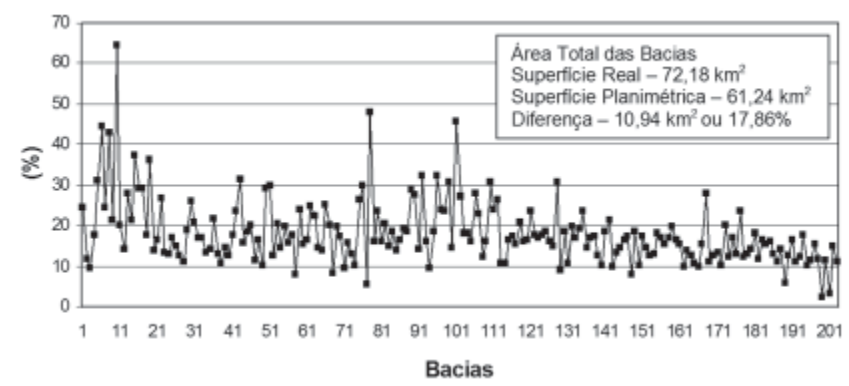

Figura 4 - Diferença percentual dos valores de área em superfície real e planimétrica por bacia de $2^{a}$ ordem

Somente a observação do comprimento da drenagem em superfície real já seria decisiva na modificação do valor de densidade de drenagem. Todavia, a diferenciação do valor da área de superfície real e planimétrica contribuem decisivamente na modificação desse índice, pois em virtude de ser uma função quadrática, a variação da área foi maior que as de comprimento de drenagem $(17,86 \%$ e $8,46 \%$, respectivamente). Assim os valores de densidade de drenagem, em quase sua maioria, se apresentam menores quando utilizadas as observações de comprimento de drenagem e área em superfície real. Esse comportamento é notado ao se avaliar a diferença do valor médio de densidade de drenagem, o qual se revelou maior quando assumidas observações em superfície planimétrica $\left(0,0047 \mathrm{~m} / \mathrm{m}^{2}\right)$ em relação ao valor quando assumidas observações em superfície real $\left(0,0044 \mathrm{~m} / \mathrm{m}^{2}\right)$. A diferença da densidade de drenagem em superfície planimétrica para em superfície real foi de $7,33 \%$ ou $0,0003 \mathrm{~m} / \mathrm{m}^{2}$.

Esse comportamento médio não se reflete na totalidade das bacias de $2^{\mathrm{a}}$ ordem, pois apesar dos valores de densidade de drenagem em superfície planimétrica terem se mostrado maior do que em superfície real, se concentrando na faixa de 6 a $12 \%$ (figura 5), a variação apresentada na figura $6(-1,82 \%$ a $27,50 \%$ ) mostrou que em duas bacias a diferença foi nula e em uma a densidade de drenagem em superfície real foi maior do que a em superfície planimétrica. A bacia que apresentou essa relação de maneira inversa ao comportamento médio foi justamente a única bacia onde a diferença percentual da área da bacia em superfície real pela planimétrica foi menor que a diferença percentual do comprimento da drenagem em superfície real pela planimétrica.

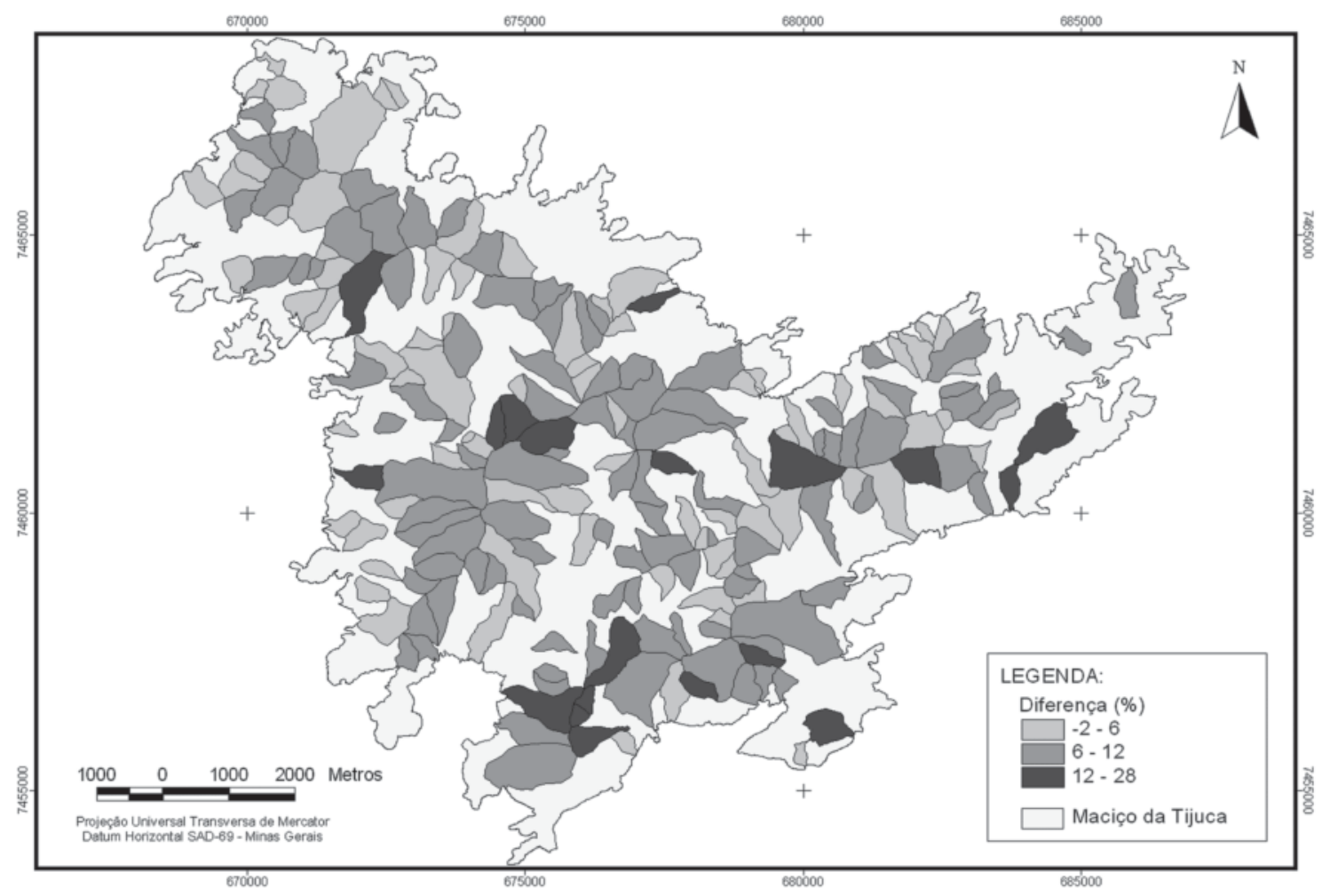

Figura 5 - Mapa de diferença percentual dos valores de densidade de drenagem em superfície real e planimétrica por bacia de $2^{a}$ ordem do maciço da Tijuca 
Os resultados da densidade de drenagem demonstraram diferentes valores, quando levado em consideração observações em superfície real e planimétrica do comprimento da drenagem e área da bacia. Essa diferença resultou na diminuição de quase todos os valores desse índice por bacia, assim esses resultados podem revelar mais precisamente a funcionalidade das bacias, em relação aos valores encontrados quando da utilização das observações em superfície planimétrica.

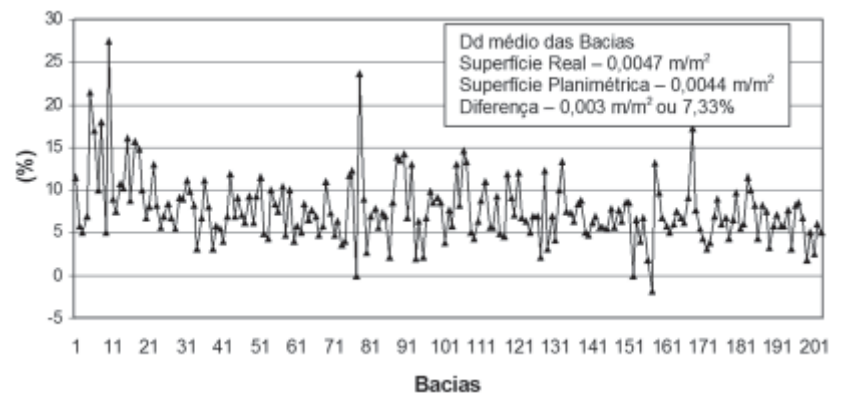

Figura 6 - Diferença percentual dos valores de densidade de drenagem em superfície real e planimétrica por bacia de $2^{a}$ ordem

\section{Índice de Eficiência de Drenagem}

A resultante analítica-integrativa de índice de eficiência de drenagem (IED), como a densidade de drenagem apresentou dois resultados, um baseado na leitura em superfície real e outro em superfície planimétrica. A comparação da média desse índice para as bacias de $2^{\mathrm{a}}$ ordem revelou uma diminuição de $0,0020 \mathrm{~m} / \mathrm{m}^{2}$ do IED em superfície planimétrica para 0,0018 $\mathrm{m} / \mathrm{m}^{2}$ do IED em superfície real, o que representa uma queda média do valor de IED de $0,0002 \mathrm{~m} / \mathrm{m}^{2}$ ou $7,92 \%$ do IED em superfície planimétrica para o IED em superfície real.
Esse quadro é semelhante ao apresentado na análise da densidade de drenagem, visto que a variação IED em superfície real e planimétrica é resultado direto da variação dessas leituras na densidade de drenagem, pois esse elemento estrutural e funcional é o único que possui variações na análise em curso. Assim, como na densidade de drenagem, o IED também apresentou diminuição em quase a totalidade das bacias de $2^{\mathrm{a}}$ ordem quando da leitura em superfície real, se concentrando na faixa de 4 a 10\%. A variação percentual de diferença das duas leituras para o IED foi de - 4 a $27,27 \%$ (figura 7 e 8). Nesse índice o número de bacias onde a variação foi nula, foi maior que a análise da densidade de drenagem, com 29 bacias. Houve ainda uma bacia que apresentou um comportamento inverso, ou seja, um maior valor de IED planimétrico para o real (4\%). Essa bacia apresentou o mesmo comportamento em relação à densidade de drenagem, que é justificado pela maior variação do comprimento da drenagem em relação à área na comparação de observações em superfície real e planimétrica.

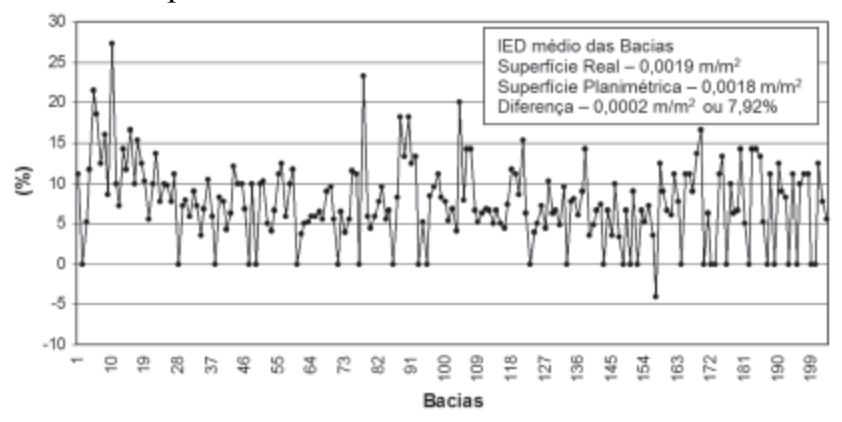

Figura 7 - Diferença percentual do índice de eficiência de drenagem em superfície real e planimétrica por bacia de $2^{a}$ ordem

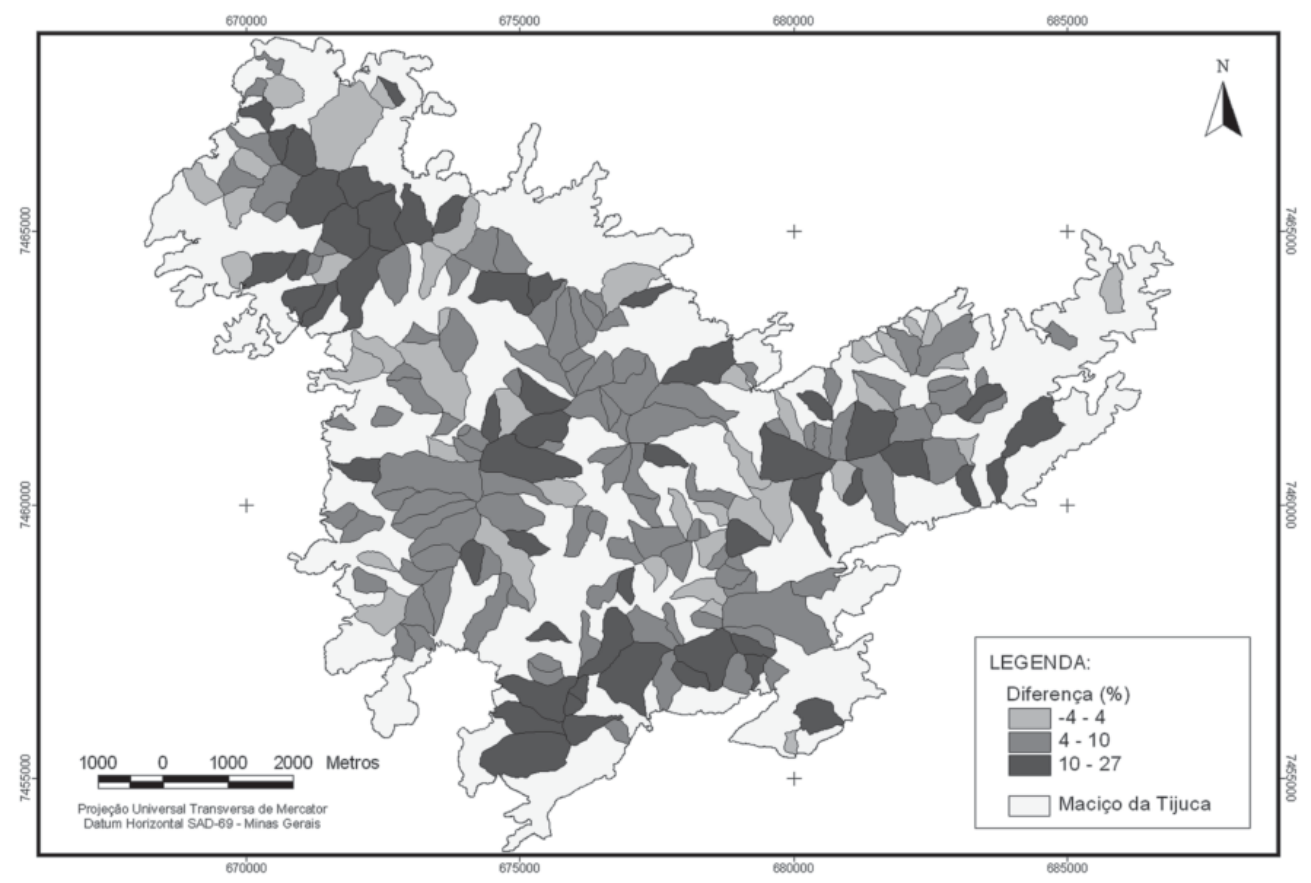

Figura 8 - Mapa de diferença percentual dos valores índice de eficiência de drenagem superfície real e planimétrica por bacia de $2^{a}$ ordem do maciço da Tijuca 
Os resultados apontam que o índice de eficiência de drenagem para bacias de $2^{\mathrm{a}}$ ordem, obtidos através da leitura da estrutura de elementos da paisagem em superfície real, pode gerar valores diferenciais de funcionalidade. Em outras palavras, a funcionalidade de capacidade de escoamento de água superficial apontada pelo índice de eficiência de drenagem é reflexo da leitura do gradiente e da densidade de drenagem, sendo que este último, ao ser analisado em superfície real interfere diretamente nos valores do índice de eficiência de drenagem.
A influência das observações em superfície real são tão decisivas na definição do índice de eficiência de drenagem que em nível de mapeamento temático, mesmo assumindo uma classificação com número pequeno de classes, para os dois tipos de observações, foram registradas 15 bacias que não se mantiveram em suas classes originais do mapeamento em superfície planimétrica, mudando para uma classe de valor inferior quando do mapeamento utilizando observações em superfície real, ou seja, demonstrando o comportamento já explicitado anteriormente (figura 9).

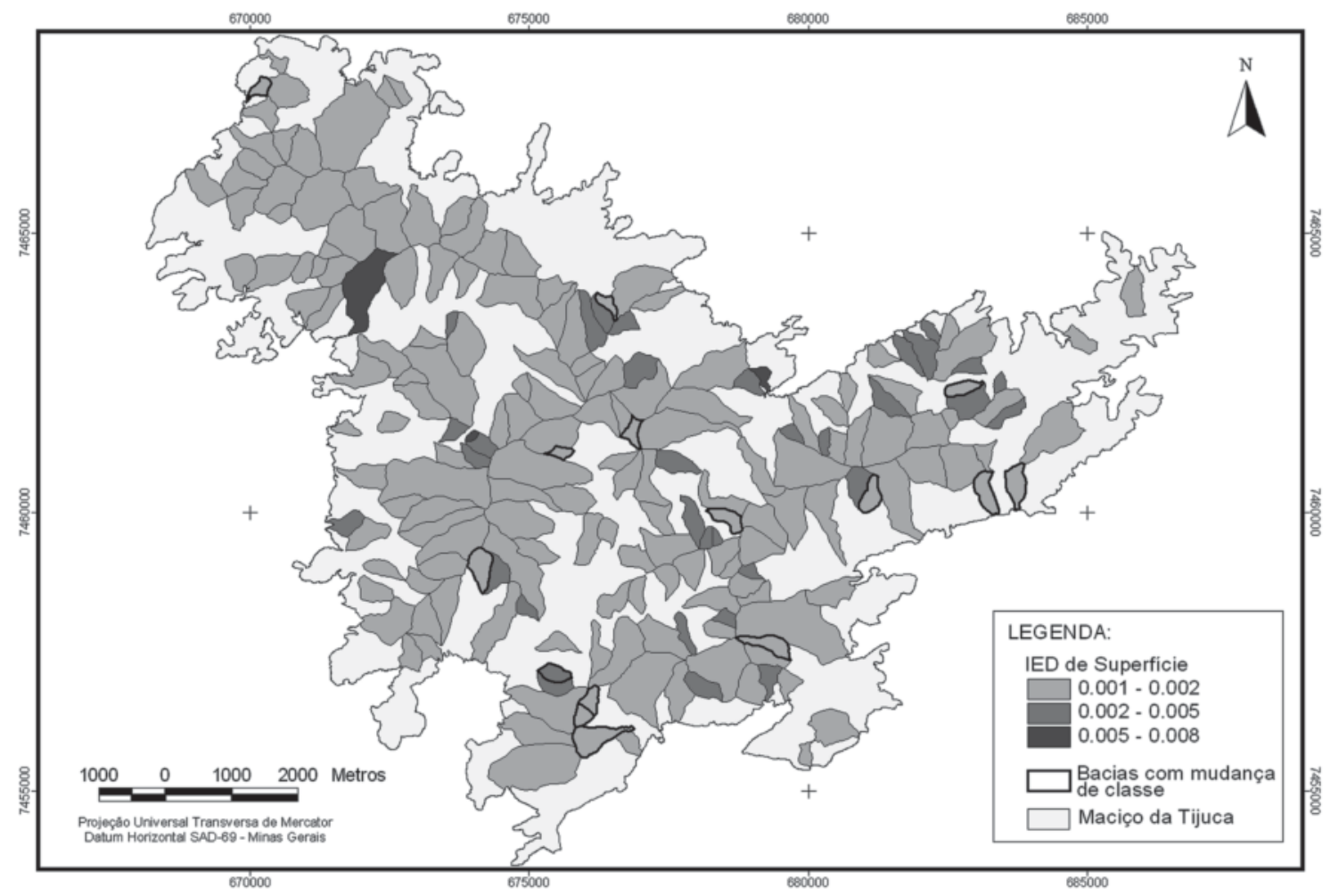

Figura 9 - Mapa de índice de eficiência de drenagem em superfície real por bacia de $2^{a}$ ordem do maciço da Tijuca, registrando bacias que mudaram de classe em relação ao mapeamento em superfície planimétrica.

\section{Conclusões}

$\mathrm{Na}$ avaliação realizada foi constatado um diferencial significativo na utilização de observações em superfície real. Este tipo de observação mostrou, na maioria dos casos, valores maiores em relação às observações em superfície planimétrica, caracterizando assim, interpretações mais próximas de leituras geomorfológicas da paisagem. Assim, levando em consideração as irregularidades expressas pela morfologia da superfície terrestre, as observações de uma paisagem deixam de ser subestimadas e podem mostrar uma realidade diferente em relação às mensurações mais usuais, em superfície planimétrica. Sobretudo, é importante ressaltar que a utilização de observações em superfície real é bastante pertinente em áreas de relevo acidentado, o que não ocorre em áreas de relevo aplainado.
Toda a análise elaborada sobre o índice geomorfológico de eficiência de drenagem demonstrou uma nova leitura em relação à estrutura e funcionalidade, que pode ser obtido na análise de uma bacia. Sem dúvida, as observações em superfície real podem ser utilizadas em outros índices ou em novas interpretações geomorfológicas, apurando cada vez mais o entendimento das dinâmicas hidrológicas e erosivas para a análise geo-hidroecológica de uma paisagem.

Cabe ressaltar ainda, que a utilização de observações em superfície real não é exclusiva para análises geomorfológicas, devendo também ser aplicada em outras áreas do conhecimento. Assim busca-se dar subsídios para melhorar a representação generalizada dos modelos conceituais em geoprocessamento, reflexo da capacidade limitada e discreta dessa representação em sistemas computacionais. 
É importante salientar que a metodologia para obtenção de observações em superfície real ainda deve ser submetida a mais investigações científicas, buscando melhorar ainda mais as observações propostas. Uma destas é a discussão do tipo de modelo digital de elevação a ser utilizado, que deve ser avaliado de acordo com a morfologia do terreno, os dados topográficos disponíveis e escala operacional assumida.

Vale ressaltar que as observações em superfícies reais são uma possibilidade que só se revelam a partir do uso do geoprocessamento em análises geomorfológicas, entretanto, ainda não são bastante exploradas. Assim busca-se uma nova leitura das variáveis geomorfológicas que podem representar um passo significativo no avanço desta ciência.

\section{Agradecimentos}

Esse trabalho faz parte da linha de pesquisa de observações em superfície real para análises geoecológicas desenvolvida no Laboratório de Cartografia do Departamento de Geografia da UFRJ (GEOCART) e tem fomento financeiro da FAPERJ e CNPq.

\section{Referências Bibliográficas}

COELHO NETTO, A.L. Hidrologia de Encostas na Interface com a Geomorfologia. In: GUERRA, A.J.T., CUNHA,S.B. (org.) Geomorfologia: Uma Atualização de Bases e Conceitos. Rio de Janeiro: Bertrand Brasil, p. 93-148, 1995.

COELHO NETTO, A.L., AVELAR, A.S., FERNANDES, M.C., LACERDA, W.A. Landslide Susceptibility in a Mountainous Geoecosystem, Tijuca Massif, Rio de Janeiro: The Role of Morphometric Subdivision of the Terrain. Geomorphology, v. 87, p. 120-131, 2007.

FERNANDES, M. C. Desenvolvimento de Rotina de Obtenção de Observações em Superfície Real: Uma Aplicação em Análises Geoecológicas. Tese de Doutorado - Programa de Pós-Graduação em Geografia, Depto. de Geografia, IGEO/ UFRJ, 263 p, 2004.
FERNANDES, M.C. Discussões conceituais e metodológicas do uso de geoprocessamento em análises geoecológicas. In: GOMES, P.C.C., BICALHO, A.M.S. (org.) Questões metodológicas e novas temáticas na pesquisa geográfica. Rio de Janeiro: Publit, p. 280-299, 2009.

FERNANDES, M.C., MENEZES, P.M.L. Avaliação de métodos de geração de MDE para a obtenção de observações em superfície real: um estudo de caso no maciço da Tijuca - RJ. Revista Brasileira de Cartografia. $\mathrm{n}^{\circ}$ 57(02), p. 154-161, 2005.

FERNANDES, M.C., AVELAR, A.S., COELHO NETTO, A.L. Domínios Geo-hidroecológicos do Maciço da Tijuca/RJ. Anuário do Instituto de Geociências. $n^{\circ}$ 29(2), p. 122-148, 2006.

GUIMARÃES, R.F. Utilização de um modelo de previsão de áreas susceptíveis a escorregamentos rasos com controle topográfico: adequação e calibração em duas bacias de drenagem. Tese de Doutorado - Programa de Pós-Graduação em Geologia, Depto. de Geologia, IGEO/UFRJ, 156 p, 2000.

HUTCHINSON, M.F. A new procedure for gridding elevation and stream line data with automatic removal of spurious pits. Journal of Hidrology. ${ }^{\circ} 106$, p. 211-232, 1989.

IPP - Instituto Pereira Passos - Cartas topográficas do município do Rio de Janeiro na escala de 1:10.000, 1999.

JENNESS, J. Surface Tools for Points, Lines and Polygons (v. 1.2) para ArcView. Disponível em: http://www.esri.com.

MEIS, M.R.M, MIRANDA, L.G.H., FERNANDES, N.F. Desnivelamento de altitude como parâmetro para a compartimentação do relevo: bacia do Médio Vale do rio Paraíba do Sul. In: Congresso Brasileiro de Geologia, 22., 1982, Salvador, Anais...Salvador: Sociedade Brasileira de Geologia, v. 4, p. 1489-1509, 1982.

STRAHLER, A.N. Equilibrium theory of erosional slopes approaches by frequency distribution analysis. Amer. J. Sci. $\mathrm{n}^{\circ} 248$, p. 673-696, 1952.

WILSON, J.P., GALLANT J.C. Terrain analysis: principles and applications. John Wiley \& Sons, 551p., 2000. 